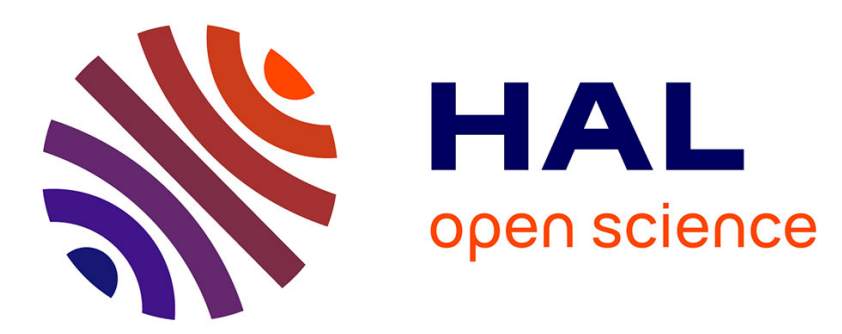

\title{
LVDC grid based on PV energy sources and multiple electrochemical storage technologies
}

\author{
Kolja Neuhaus, Jérémy Dulout, Corinne Alonso
}

\section{To cite this version:}

Kolja Neuhaus, Jérémy Dulout, Corinne Alonso. LVDC grid based on PV energy sources and multiple electrochemical storage technologies. Smart World Congress 2016 (2016SWC), Jul 2016, Toulouse, France. 8p., 10.1109/UIC-ATC-ScalCom-CBDCom-IoP-SmartWorld.2016.0155 . hal-01698934

\section{HAL Id: hal-01698934 \\ https://hal.science/hal-01698934}

Submitted on 1 Feb 2018

HAL is a multi-disciplinary open access archive for the deposit and dissemination of scientific research documents, whether they are published or not. The documents may come from teaching and research institutions in France or abroad, or from public or private research centers.
L'archive ouverte pluridisciplinaire HAL, est destinée au dépôt et à la diffusion de documents scientifiques de niveau recherche, publiés ou non, émanant des établissements d'enseignement et de recherche français ou étrangers, des laboratoires publics ou privés. 


\title{
LVDC grid based on PV energy sources and multiple electrochemical storage technologies.
}

\author{
Kolja NEUHAUS, Jeremy DULOUT, Corinne ALONSO \\ Laboratoire LAAS-CNRS \\ 7, avenue du Colonel Roche \\ BP 5420031031 Toulouse cedex 4 \\ E-mail : kolja.neuhaus@laas.fr
}

\begin{abstract}
In the global context of the electric power grid modernization, storage of electricity is a crucial issue. Nowadays, energy storage systems (ESS) are used more and more in positive energy buildings in conjunction with new Low Voltage Direct Current (LVDC) grids. However, the impact of renewable energy sources (RES) on ESS is not well known. The main objective of this article is to determine a systematic methodology to study energy data from a positive energy building in order to determine the impact on ESS dedicated to be included in smartgrids. The aim is to obtain comparative results in normalized working conditions and determine charge/discharge cycles. Clustering methods were compared to choose the more adapted one to treat the stored data of energy production and consumption during more than three years in our experimental platform in LAAS-CNRS, Toulouse. Each type of cycle will help further study in order to estimate its impact on efficiency and lifetime of ESS and then choose the more adapted element for each application.
\end{abstract}

Keywords - PV production ; positive energy building ; data clustering ; data analysis; battery cycle ; efficiency

\section{INTRODUCTION}

Progressive integration of renewable energy sources (RES) like photovoltaic or wind energy induces new constraints on classical electric power grids. All around the world, researches are conducted on the design of electrical grids to ensure higher efficiency and robustness of electric distribution from producer to consumer in addition to real-time control and response to energy demand [1]. New power grid topologies are developed in order to reduce transmission losses: high voltage direct current grids (HVDC) for long distance [2] and Low Voltage Direct Currents (LVDC) for local energy exchanges [3] well adapted for buildings. Any type of grid using RES needs local energy storage systems (ESS) to compensate the intermittence of production. This paper presents work in progress done to design an optimal LVDC grid based on analysis of real consumption and production data. Preliminary studies are needed to analyze production/consumption intermittency based on new profiles identified by data clustering methods. After a brief description of the context of energy optimized buildings and the new smart-grid challenge, a method of clustering used to create normalized discharge/charge cycles adapted to a real application is proposed. In this study, we choose to treat independently intermittent photovoltaic production and the building's consumption. The chosen cluster analysis method is able to identify meaningful data from large real-scale data sets. Two examples illustrate this purpose: the identification of "typical" photovoltaic productions with different current profiles depending on meteorological conditions and geographic position and "typical" electrical consumption profiles for an energy optimized building in the ADREAM building. The main difficulty when studying impact on storage devices is to obtain normalized charge/discharge cycles based on real data to study their effects on each type of storage component. Another difficulty is to apply the same constraints in all storage elements and to identify the impact of these cycles on batteries in comparison to standard test cycles.

First, a brief reminder of the current state of energy grids and the principle of smart-grid development is presented. In the second part, the ADREAM test platform at LAAS-CNRS and the nature of collected data is introduced. A synthesis of solar producible studies concerning solar intermittency is given. In the third part, cluster analysis principles are remembered through a brief state of the art of data clustering methods. The chosen one for our study is then presented. Some examples using the energy data from the building are given in the fourth part to illustrate how data clustering can compute massive data with diverse criteria. Photovoltaic production data and electrical consumption data from the building are studied. In the last case, the variation between each profile is highly dependent on presence or not of consumers. Different families of storage elements will be tested in same conditions. Our long-term goal is to observe their characteristics progressing in time and their dependency on the working environment.

\section{ENERGY GRIDS AND THEIR EVOLUTION TO SMART GRIDS}

As energy demand is constantly increasing and fossil resources are limited, RES have been developed in the past decades [4]. Nevertheless, the structure of actual power grids is not really adapted to incorporate all these sources, as they are not commendable and highly intermittent and inducing risks of grid instability [5]. In order to inject energy from RES while maintaining an adequate level of energy quality, the grid needs to evolve, progressively incorporating smart control and metering technology.

\section{A. Vertical grid structure}

Historically, the energy supply chain was constructed vertically from producers to consumers. It was operated by public utilities, differentiating generation, transmission, distribution and supply steps. This system was targeting to minimize the total system cost by exploiting economies of scale for each step, resulting in construction or large generation plants to be located near to primary fuel sources or near large 
industrial customers. After the oil crisis (1973), the main focus in energy supply was security of supply, creating redundancies in the grid system. In this context of large centered energy production, the whole energy distribution was created to match loads to the generation, meaning that produced energy had to be consumed at all times and grids have been designed to transport energy unidirectional from generation plants to consumers. In addition, grid operators have been lacking detailed knowledge of customer load profiles due to lack of smart metering technologies and therefore were only able to adapt consumption to production [6]. At the same time, some social influence factors such as high quality service expectations and environmental awareness were not as important as nowadays. As the general demographic, economic and technologic resource abundancy situations are changing progressively, the energy grids must be adapted, taking in account their purpose in the future.

\section{B. Smart grids and horizontal structure of future grids}

In the years 2000s, the energy market was liberalized and the previously vertical energy supply chain had to be reorganized differently as every element in the supply chain except grid operation is now subject to competition. On the production side, many different companies offer their product that can be issued from many different sources to the consumer through the general grid. On the consumer side, the choice of the energy provider is free and self-production or selfconsumption becomes a viable option as decentralized energy production technology advances. The development of sustainable distributed generation such as photovoltaic, small combined heat/power plants or solar thermal systems are an opportunity for carbon dioxide reduction and security of energy supply while they also introduce the new challenge of integrating many small and intermittent energy sources in the general grid and maintaining the same level of quality in energy supply. This implies self-consumption and therefore lower utilization of local networks, bidirectional energy flow in grids to handle local excess generation or economical billing problematics based on energy provenance.

In response to these challenges, the structure of energy grids has to be redesigned from a unidirectional system structure to a more interactive one where production and consumption can be mitigated. Usage of new technologies such as smart sensors, digital data gathering and analysis, emerging electronic converters and commands [7] must constitute the core of future smart energy grids. Exact matching of both energy production and consumption in quantity and quality coupled with appropriate controlled bidirectional grid structures are the key points of the development of these smart grids.

As demand grows, reducing energy losses and using energy in its most primary form become new challenges. For this purpose, along with technological advancement in electrical converters, new types of grid structures such as the LVDC grid emerge to minimize the number of conversion stages between energy production and local consumption. Local grid structures such as LVDC or LVAC necessitate energy storage devices such as batteries as buffers to store intermittently produced energy, these grids could be isolated or inter connected to others. However, combining production, storage, distribution and consumption such as in positive energy buildings is a real challenge of design.

\section{ADREAM PLATFORM, ENERGY OPTIMIZED BUILDING}

Current researches on new power grid topologies including ESS are assessed through the energy optimized building platform ADREAM [8] in LAAS-CNRS (fig.1). This building has been designed to be a demonstrator but also a large-scale research tool for real-scale positive energy buildings. With this platform, constant innovations on energy source management, sensor quality and supervision can be validated through multiple different projects. This platform has over 7000 sensors giving information every minute about every installed system in the building. All data are collected in a database (over 3 years of data). The sensors provide information about heating systems and acclimatization, lighting systems, quality of environment (meteorology, temperatures...), PV production, electric consumption and storage, camera network services, movement and localization services, communication networks (ZigBee, Wi-Fi...), robotic research systems and supervision tools. This building is covered with $720 \mathrm{~m}^{2}$ of PV panels with a total peak power of $100 \mathrm{~kW}$. The PV surface is divided in four main different zones (Table 1).

\begin{tabular}{|c|c|c|}
\hline Roof & PV TE2200 & inclination: $10^{\circ}$ \\
\hline Wall & PV TE2200 & inclination $: 90^{\circ}$ \\
\hline Terrace & PV TE2200 & $\begin{array}{c}\text { Adjustable inclination: } \\
0^{\circ} \text { à } 90^{\circ}\end{array}$ \\
\hline Facade & Double glass & inclination $: 65^{\circ}$ \\
\hline
\end{tabular}

Table 1. Différent zones of the photovoltaic system at ADREAM platform, LAAS-CNRS, Toulouse

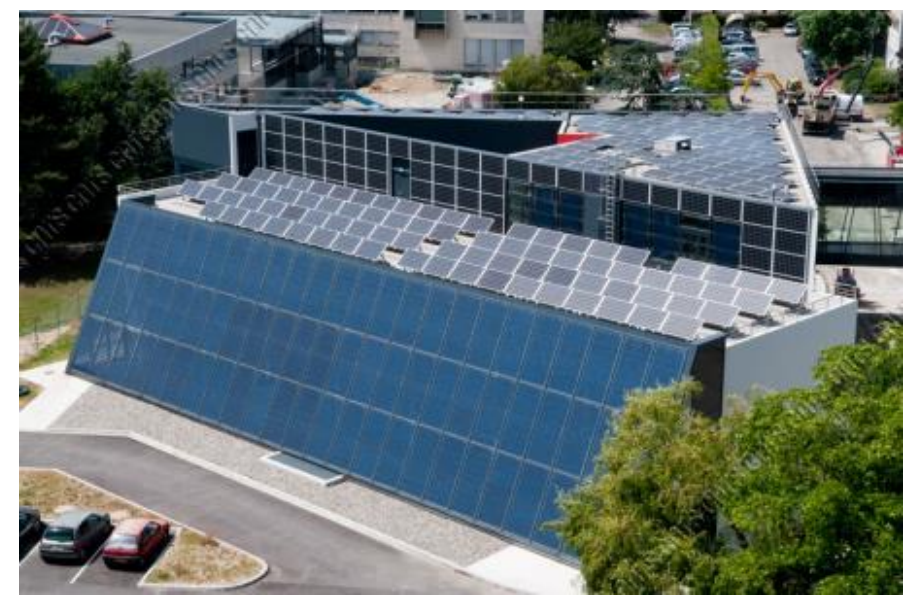

Fig. 1. Global view of the ADREAM Experimental Platform on energy exchanges, LAAS-CNRS Toulouse

Today, several projects of AC and DC microgrids with different ESS are developed in the ADREAM building. One of them is focused on designing a storage system for a conventional AC grid integrating a large production of PV. An other demonstrator is developed: a DC microgrid only supplied by a PV source will provide "green energy" to 
servers of a datacenter and to a show flat (with low lighting consumption (LED), many sensors ready for the internet of things (IoT), low voltage grid type power over Ethernet (PoE)...). This LVDC microgrid will provide data to compare structures and energy efficiency between DC/AC and DC/DC conversion.

\section{A. Solar irradiation and $p v$ production}

Studying solar irradiation quality and its intermittence is one of the PV energy research axes of the ISGE team (Intégration des Systèmes de Gestion d'Energie) in LAASCNRS [9], [10]. In order to design optimized energy management systems using photovoltaic production, a good understanding and knowledge of the solar producible is needed.

Generally, global solar irradiation on a given terrestrial surface could be decomposed into three distinguished parts. According to Bernard [11], we can note different irradiations on a given surface by their origins (fig. 2).

- The Direct radiation (S), corresponding to the radiation received directly from the sun when the sky is clear.

- The Diffuse radiation (D) is the radiation coming from the whole atmosphere, due to diffraction. It is more important when the sky is cloudy.

- The Reflected radiation (R) coming from other surfaces nearby (floor, water, glass, walls ...) by reflection of the sunlight on them.

The global irradiation $(\mathrm{G})$ on a surface can be written as the sum of them:

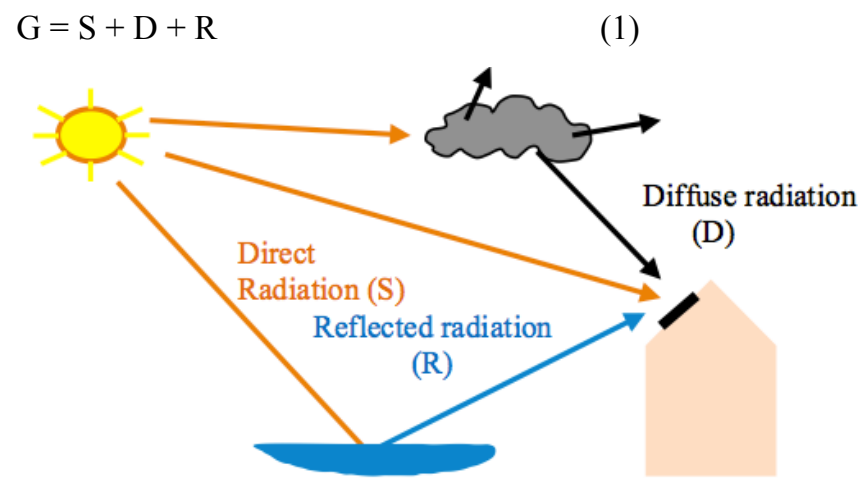

Fig. 2. Incoming radiation on a photovoltaic surface

The quality of estimation on this global irradiation depends on the quality of measures of each type of irradiance needing a lot of sensors. A brief description of our experimental site is done below.

\section{B. Sensors and instruments}

The ADREAM platform is equipped with different types of solar radiation sensors in order to study solar producible and then modeled it. With this type of precision, it can be easier to evaluate performances of each part of PV systems in each geographic site of the world. Nevertheless, we want to develop precise models able to estimate solar irradiation in real time but also to drastically reduce sensors and have a mobile data station able to be employed in every site in the future.

In a first approach, four pyranometers from Kipp\&Zonen have been placed on the top of our experimental building as seen in the fig. 3, three referred CMP3 and one more precise is referred CMP10. These sensors are all wired to National Instruments acquisition card. The global bench constitutes of an automatized measuring system allowing the study solar producible and its intermittence with a high precision (4\% to $5 \%$ uncertainty). This type of test bench helps us to analyze other data brought by the sensors located in photovoltaic modules, converters and globally the behavior of all elements of the building. They have been fixed on inclinable stands in order to measure global irradiation $(\mathrm{G})$ for different inclinations.

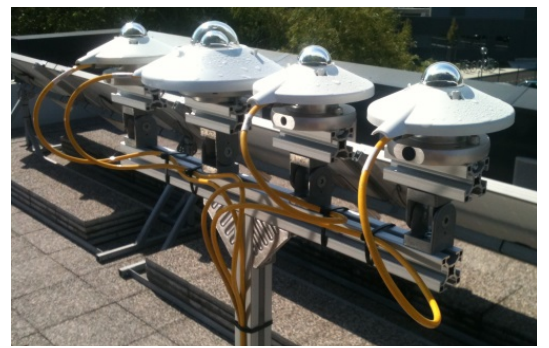

Fig. 3. Solar irradiation sensors on their inclinable stand.

In a second approach, to be more precise in the repartition on direct and diffuse irradiations, the CMP10 pyranometer has been set up on a solar ring structure (figure 4).

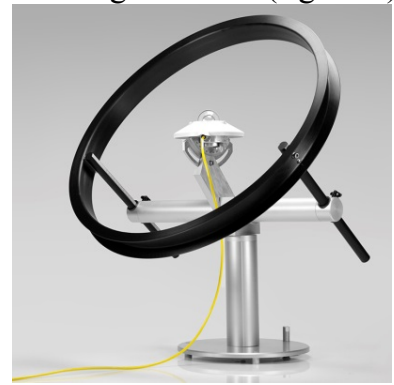

Fig. 4. Pyranometer doted with a solar ring to measure diffuse and reflected irradiation.

A solar ring system hides the irradiation sensor from the direct solar radiation through the entire day by covering the sun's path accordingly. It allows measures of the irradiation diffused by the rest of the atmosphere and the irradiation reflected by nearby surfaces. A more precise model has been elaborated [12].

The study of solar radiation and precise modeling of solar producible permits to identify the quality of the energy data provided by the sensors on the PV systems and general electric grid of the building. This previous work gives a high precision comparison and verification point for PV performance based on the solar radiation and meteorology. High quality measures with pyranometers on different inclinations provide with a reliable way to validate the quality of other PV energy measures from the buildings sensors. Figure 5 shows an 
example of comparison between daily irradiation data from the CMP pyranometers and data from the database server.

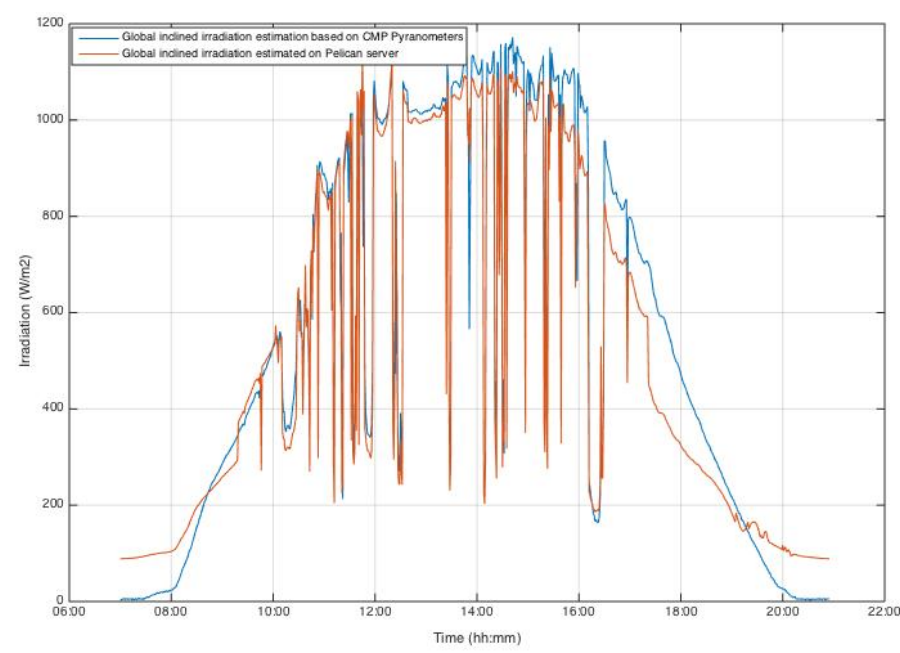

Fig. 5. Daily solar irradiation data from CMP pyranometers (Blue) and data from ADREAM's server (Red)

Data from the sensor systems in the ADREAM platform must be analyzed to improve knowledge of production and consumption in an energy optimized building and progress in smart energy managing. The next chapter introduces cluster analysis methods used to compute large data banks that are adapted to this context.

\section{Cluster ANALYSIS}

Cluster analysis or clustering is the task of grouping a set of objects in such a way that all objects in the same group (called a cluster) have a maximum of similitude compared to other objects belonging to other groups (clusters). It is a common technique used to make statistical data analysis. This type of analysis is able to identify general trends or typical similarities in large data and has been proven to be usable for PV power data [13]. Cluster analysis can be achieved with many different methods and algorithms. The main difference between them is the definition of what constitutes a cluster and how to efficiently find it. Tasks to achieve clustering can be described as iterative knowledge discoveries that involve many trials and iterations to find adequate clusters with desired properties. For the energy production and consumption data, a specific clustering algorithm has to be chosen from those used in literature.

\section{A. Different types of cluster analysis algorithms}

In the literature, four main different families of clustering algorithms could be found. The first one is named hierarchical clustering [14]. It consists to calculate distance between objects (data points) to connect the closest objects in a same cluster. With this method, the maximum distance that connects two objects in a cluster defines each cluster. In the second family named centroid based clustering [15], each cluster is represented by a central vector (or centroid). Objects are assigned to clusters by their distance to the central vector of each cluster. The third type of clustering named Distribution- based clustering uses mathematical probability distribution models such as a Gaussian one. Clusters are defined as objects belonging to the same distribution. In the last group named density-based clustering [16], clusters are defined as areas of higher density than the reminder of the data set. Objects in these sparse areas are usually considered to be noise and border points.

In our energy context, the main goal is to identify typical profiles representing general trends in daily electrical power productions and consumptions based on meteorological and human usage scenarios. As we need to identify which days of data are the most representative ones for large parts of the total data, the chosen method must use data vectors as reference points for each cluster. A centroid based clustering method seems to be more adapted because this method uses central vectors for each cluster. Each resulting central vector represents the general trend of its cluster and can therefore be used as a typical daily power characteristic, representing all other days in the same cluster. In this case the interesting data for this application will be the centroids of each cluster.

\section{B. Clustering daily power data using K-medoids algorithm}

The most common clustering method based on centroids in use for energy applications is the K-means algorithm described in [17]. In this algorithm, the centroid of each cluster is defined as the mean value of the cluster. This algorithm is not directly usable in our application, as we want to identify the most "typical" and representative daily curves among the data but do not want to use a mean value as centroids because a mean daily curve is not representative of a realistic situation. Instead, we want to use one of the daily profiles of each cluster as the representative vectors for each cluster. One centroid based clustering algorithm that is particularly adapted to our study is the K-medoids algorithm, which is a derivate of the K-means algorithm. In this algorithm, the centroid element of each cluster is the one data vector that is the closest to the mean vector of the cluster (the medoid). In our application, the medoid of each cluster of daily power vectors (electrical power vs time) will be identified as the representative vector for this clusters scenario. Figure 6 shows an algorigram of the Kmedoids method we use for treating the data. 


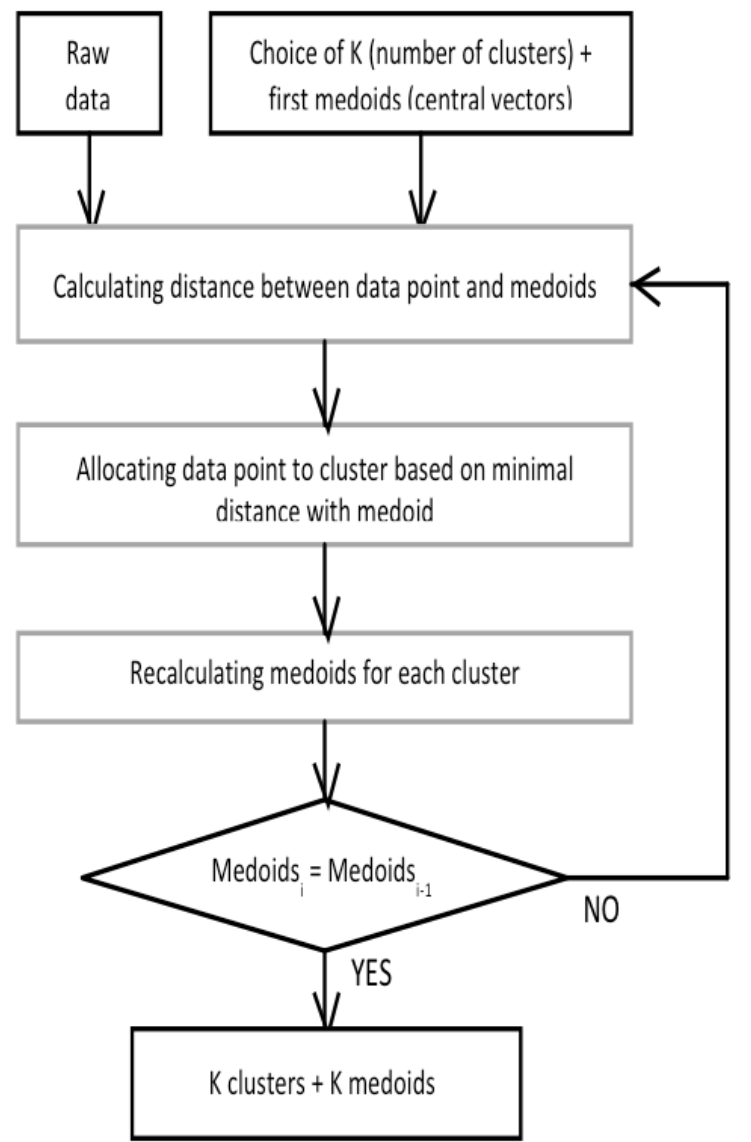

Fig. 6. Algorigram for the K-medoids clustering method.

The algorithm is initialized with the raw data. The number of desired clusters $(\mathrm{K})$ is chosen by the user. For example, the user defines or chooses one daily data (here one typical day power behavior array) as medoid for each cluster. An iterative loop begins. For each data element, the distance between it and each medoid is calculated. Each data point is then assigned to the closest medoid, forming the clusters. After this step, the most central and representative vector of each cluster is defined by the program as the new medoid of the cluster. At this point the medoids are changing on every iteration of the loop until the clusters do not evolve anymore. This means that when the data vectors of a cluster do not change between two iterations, the medoid stays the same. The algorithm stops when the $\mathrm{K}$ medoids have not changed between two iterations. At this point, the raw data has been partitioned in $\mathrm{K}$ groups (clusters) of daily curves. Each cluster is represented by one central element (the medoid), a typical daily curve.

This data partitioning method is applied to two sets of data from the ADREAM platform: daily PV production data from $100 \mathrm{kWp}$ of photovoltaic panels and electrical consumption data from the building.

\section{PRODUCTION AND CONSUMPTION PROFILES FOR THE BUILDING}

Results obtained using the K-medoids algortihm on the PV production and electrical consumption data from the ADREAM platform are presented in this part. The typical profiles resulting from this application are shown as daily instantaneous power versus time curves.

\section{A. Study of PV production data}

Instantaneous daily power data with a one-minute sampling rate for the year 2015 is accessible on the ADREAM Photovoltaic platform. Using the K-medoids method explained in the above section, this data is processed with four different clusters. The typical profiles obtained are described on fig: 7 .

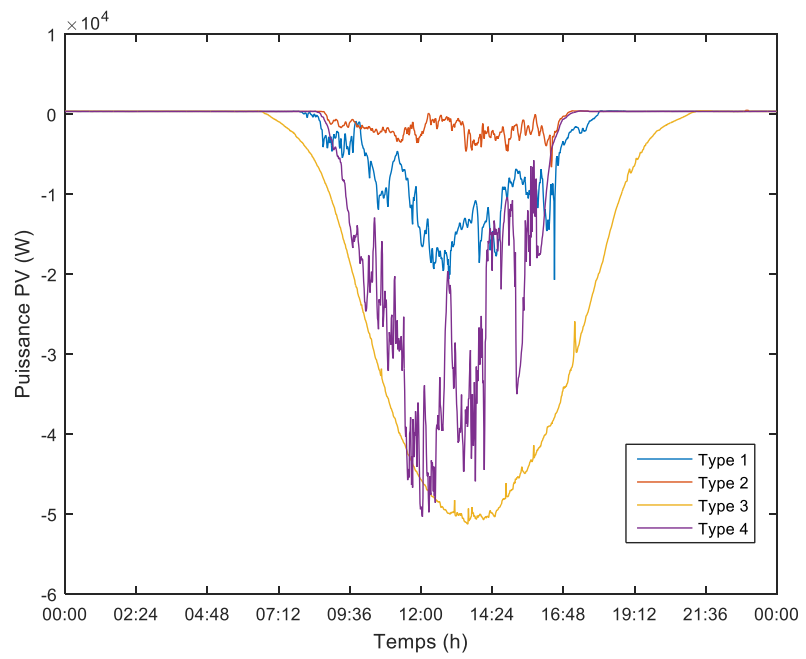

Fig. 7. Different types of daily PV power profiles identified with K-medoids clustering.

The four resulting medoids define typical daily PV production profiles. They can be labeled "low intermittent solar radiation" (type 1), "low uniform solar radiation"(type 2), "uniform strong solar radiation"(type 3) and as "strong intermittent solar radiation"(type 4). The shown PV power profiles are negative as these graphs represent "consumed power". Identifying these daily production profiles is a necessary step to study realistic impact of PV intermittence on electrochemical storage devices. Tests concerning their impact on state of charge (SOC) and state of health ( $\mathrm{SOH}$ ) of storage devices in realistic energy optimized building conditions will be made using these profiles.

\section{B. Study of building electrical consumption data}

As for PV production data, K-medoids algorithm is used on the total electrical consumption data from ADREAM platform in 2015 with a one minute sampling rate. For this study a number of clusters of $\mathrm{K}=3$ has been chosen. The following results are obtained: 


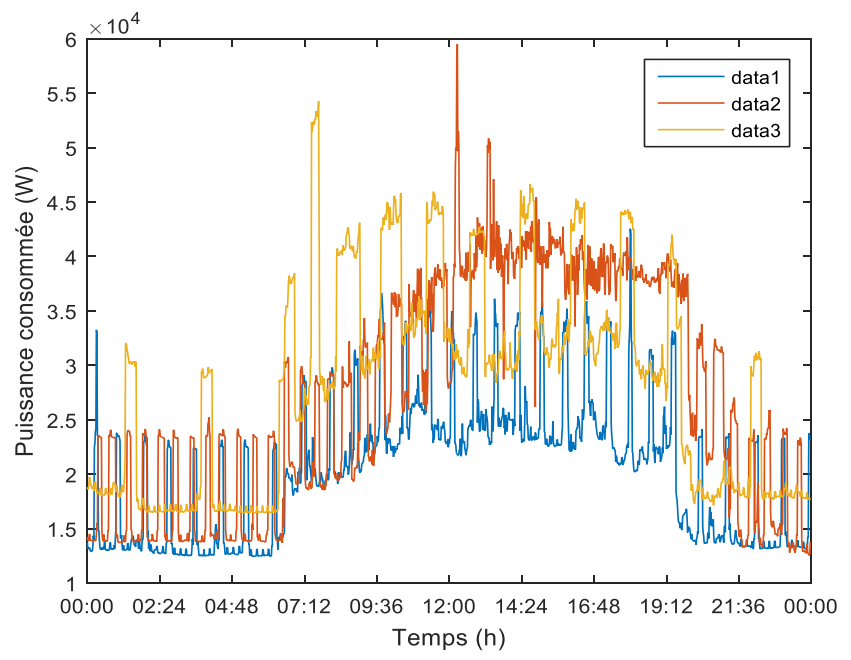

Fig. 8. Different types of daily profiles for power consumption identified with K-medoids algorithm

These three different profiles are mostly variating in amplitude and thickness of the visible repeating power plateau. These plateaus are due to temporary activation of the heat pumps for both heating and cooling of the building. A change in overall amplitude between data1 and data 3 curves is mostly due to different commands of hot water circulation pumps between winter and summer. These typical daily consumption profiles will serve to test the response of storage devices to realistic discharge profiles for an energy optimized building.

The typical production and consumption profiles shown in this part are the first ones obtained through data clustering. They will constitute a base to define charge/discharge cycles applied to storage elements. Thus, these types of cycles are more realistic battery charge/discharge profiles applied to an energy-optimized building. They have to be tested on different technologies of electrochemical energy storage described in the following part. This part of our study on storage unit tests are work in progress and cannot be exposed in this paper in their current state. In particular, we do not have results with required precision and sample time for this paper.

\section{STORAGE UNITS ADAPTED FOR ENERGY OPTIMIZED BUILDINGS}

Storage of electrical energy is one of the key points for successful renewable energy development. Several different technologies exist nowadays and it is essential to identify the most adapted ones for usage in an energy-optimized building. Determinant factors for comparison [18] are battery lifetime (depending on depth of discharge DOD per cycle), the efficiency of the cells (ratio of charged/discharged energy), their price and their environmental footprint. These storage devices must be able to store as much as possible of the overproduction from renewable sources and must be able to restitute this energy as needed when the production is not sufficient to supply for the buildings consumption. In this case the stored energy is discharged over several hours, meaning specific energy $(\mathrm{Wh} / \mathrm{kg})$ is more valuable than specific power.

For our first approach of cycle tests, three technologies of batteries have been selected a priori more adapted to building context: Lead acid, Lithium iron-phosphate and hybrid LIC lithium-supercapacity.

\section{A. Lead acid batteries}

The lead acid battery technology [19] is the oldest rechargeable accumulator technology, existing since 1259 . It is very commonly used today and different variations exist for different applications (energy storage, power storage). Its specific energy is relatively low (33 to $42 \mathrm{Wh} / \mathrm{Kg}$ ) but is interesting for stationary energy storage due to its low cost.

The AGM (Absorbent Glass Matt) and OPzV (using tubular electrodes) are the most adapted lead-acid technologies for photovoltaic production and especially in energy optimized buildings. The electrolyte is jellified in hermetic sealed battery blocs, minimizing maintenance needs. These specific types of lead acid batteries can have a lifetime of 500 to 1500 cycles at $80 \%$ depth of discharge (DOD) against 300 to 600 cycles for other lead acid technologies. Their self-discharge is a slow $3 \%$ to $10 \%$ per month [18].

\section{B. Lithium iron phosphate batteries}

Lithium-ion batteries [20] are industrially produced since the beginning of the 1990's and is the most used storage devices today on the electronic consumer market.

Mobile devices generally use mixed cobalt-lithium batteries $\mathrm{LiCoO}_{2}$ for their high energy density. The lithium iron phosphate battery $\mathrm{LiFePO}_{4}$ shows a bit lower energy density $(\sim 90 \mathrm{Wh} / \mathrm{Kg})$ but a longer lifetime (2500-3000 cycles at $80 \%$ DOD) and a better security, which makes it especially adapted for stationary high energy storage. The price of the $\mathrm{LiFePO}_{4}$ technology is higher than for lead acid batteries but stays competitive due to its increased lifetime, meaning less replacing and maintenance costs. It also has a better resistance to fast discharges and deep discharges while maintaining a low self-discharge rate (around 3\% per month). Low voltage variation while discharging greatly reduces the complexity of the voltage regulation for this technology. It is therefore one of the best adapted batteries for inhabited environment when used with a protection system against overvoltage and overcurrent.

\section{Lithium supercapacity chemical hybrid LIC}

The intermittency of photovoltaic production can be problematic for energy storage. Hybrid systems using lead acid and lithium ion batteries with supercapacities are largely studied in this domain and tend to improve the smoothing of production or consumption peaks directly related to intermittency.

Lithium supercapacities (LIC)[21] are electrochemical hybrid storage devices that have been created recently by combining principles of lithium-ion batteries and doublelayered supercapacities (EDLC). EDLC is a technology halfway between batteries and electrolytic capacitors that are able to store more energy than a classical capacitor. The 
energy can be stored and released at high power as in a classical capacitor. The main goal of this hybridization is to combine the benefits of each technology in terms of energy density, power density, charge/discharge speed and lifetime. This new hybrid technology is emerging like a potential alternative to electrical hybridization of lithium-ion batteries and EDLC, being used both as energy and power source.

Manufacturers show a very high number of capacitive cycles $(>100000)$ and a long lifetime, making this technology very interesting for stationary renewable energy structures. Additional studies are needed to verify daily cycling withstanding. This type of hybrid seems very promising for renewable energy applications. LAAS-CNRS, associated to CIRIMAT through the Neocapus project are studying this type of hybrid storage to improve their performance and modeling it.

\section{CONCLUSION}

To conceive a local optimized energy grid based on photovoltaic sources, a good knowledge of the solar producible, its intermittence and its production is needed. Studying typical PV production profiles permits to identify the quantity of available and storable energy depending on the meteorological scenario. Four types of production profiles have been identified in addition to three types of consumption profiles for the building. The impact of these realistic profiles can be tested on batteries and compared to standard test profiles. Identification of storage technologies adapted for energy optimized buildings permits an efficient dimensioning and an energy gain through optimization of self-consumption. Lead-acid AGM, OPzV and lithium iron phosphate batteries are particularly adapted to stationary renewable energy production structures. Electrochemical hybrid LIC has interesting technical specifications and seems promising.

One key point in energy transfer optimization is a better knowledge of storage units. For this purpose, a model of state of charge (SOC) and state of health (SOH) in battery storage units is necessary and has to be done for the next step of this work. Once developed, storage models can be tested using the typical and realistic profiles obtained in this first work.

\section{AKNOWLEDGEMENTS}

This work is done in the Neocampus project context [22] and concerns in particular three laboratories: CIRIMAT, LEPMI and LAAS. The objective is to conceive an LVDC grid based on renewable energy sources and electrochemical storage devices that are adapted to any type of solar scenario.

\section{REFERENCES}

[1] M.S. Hossain , N.A. Madlool, N.A. Rahim, J. Selvaraj, A.K. Pandey, Abdul Faheem Khan, "Role of smart grid in renewable energy: An overview", Renewable and Sustainable Energy Reviews 60 (2016) 1168-1184, Elsevier
[2] A. Kalair, N. Abas, N. Khan,"Comparative study of HVAC and HVDC transmission systems", Renewable and Sustainable Energy Reviews 59 (2016) 1653-1675, Elsevier

[3] Jackson John Justo a, Francis Mwasilu a, Ju Lee b, Jin-Woo Jung," AC-microgrids versus DC-microgrids with distributed energy resources: A review", Renewable and Sustainable Energy Reviews 24 (2013) 387-405, Elsevier

[4] C. D. Parker, "Lead-acid battery energy-storage systems for electricity supply networks," J. Power Sources, vol. 100, no. 1, pp. $18-28,2001$.

[5] Achim Woyte, Vu Van Thong, Student Member, IEEE, Ronnie Belmans, Senior Member, IEEE, and Johan Nijs, Senior Member, IEEE "Voltage fluctuations on distribution level introduced by photovoltaic systems",IEEE TRANSACTIONS ON ENERGY CONVERSION, VOL. 21, NO. 1, MARCH 2006

[6] D. schwabeneder, H. Auer, "Optimising Hybrid energy grids for smart cities", WP2 Technical, Economical and Social Benefits, Report on Technical, Economical and Social Patterns of Energy Service Provision, TUW-EEG, feb. 2015

[7] F. Locment, "Contribution à la modélisation et à la commande des sources renouvelables dans les micro-réseaux urbains", HDR UTC, déc. 2015.

[8] ADREAM, Architectures dynamiques reconfigurables pour systèmes embarqués autonomes mobiles. [Online]. Laboratoire d'analyse et d'architecture des systèmes-CNRS. Available on : https://www.laas.fr/public/fr/adream

[9] M. Bressan, « Développement d'un outil de supervision et de contrôle pour une installation solaire photovoltaïque ", Thèse délivrée par l'Université de Perpignan Via Domitia, Collège Doctoral du Languedoc-Rouissillon, 2014

[10] Y. Aboukhait, "Estimation de production des installations PV pour différentes inclinaisons basée sur un modèle d'ensoleillement", LAAS-CNRS, Université Paul Sabatier, 2014.

[11] Jacques Bernard, "Energie solaire, Calculs et optimization", France: Ellipses Edition Marketing S.A., 2004.

[12] K. Neuhaus, M. Bressan, C. Alonso, «Optimisation de modèles d'ensoleillements à des fins d'estimation de production photovoltaïque du bâtiment ADREAM », internship report, LAASCNRS, Université Paul Sabatier, 2015

[13] Amr A. Munshi, Yasser A.-R.I. Mohamed, "Photovoltaic power pattern clustering based on conventional and swarm Clustering methods", Elsevier, Solar Energy 124 (2016) 39-56.

[14] Everitt, Brian (2011). "Cluster analysis". Chichester, West Sussex, U.K: Wiley. ISBN 9780470749913

[15] Lloyd, S. (1982). "Least squares quantization in PCM". IEEE Transactions on Information Theory $28(2)$ : 129 137.doi:10.1109/TIT.1982.1056489

[16] Ester, Martin; Kriegel, Hans-Peter; Sander, Jörg; Xu, Xiaowei (1996). "A density-based algorithm for discovering clusters in large spatial databases with noise". In Simoudis, Evangelos; Han, Jiawei; 
Fayyad, Usama M. Proceedings of the Second International Conference on Knowledge Discovery and Data Mining (KDD-96). AAAI Press. pp. 226-231. ISBN 1-57735-004-9. CiteSeerX: 10.1.1.71.1980.

[17] Anil K. Jain, «Data clustering: 50 years beyond K-means», Pattern Recognition Letters 31 (2010) 651-666, Elsevier.

[18] D. Linden, T.B. Reddy,"Handbook of batteries, third edition", McGraw-Hill inc. 2002, United States of America.

[19] Pierre Mayé, “Générateurs électrochimiques”, 2010 DUNOD

[20] Gholam-Abbas Nazri, Gianfranco Pistoia ,"Lithium Batteries, science and technology”, 2004 Kluwer Academic Publishers

[21] Danilo Porcarelli, Davide Brunelli, Luca Benini, "Characterization of Lithium-Ion Capacitors for low-power energy neutral wireless sensor networks", 2012 IEEE

[22] Neocampus, Démonstrateur de campus connecté, innovant, intelligent, durable. [Online]. IRIT. Available on : https://www.irit.fr/neocampus 